\title{
Shared temporal cognitions as substitute for temporal leadership: An analysis of their effects on temporal conflict and team performance
}

Citation for published version (APA):

Santos, C. M., Passos, A. M., Uitdewilligen, S., \& Nubold, A. (2016). Shared temporal cognitions as substitute for temporal leadership: An analysis of their effects on temporal conflict and team performance. Leadership Quarterly, 27(4), 574-587. https://doi.org/10.1016/j.leaqua.2015.12.002

Document status and date:

Published: 01/08/2016

DOI:

10.1016/j.leaqua.2015.12.002

Document Version:

Accepted author manuscript (Peer reviewed / editorial board version)

Please check the document version of this publication:

- A submitted manuscript is the version of the article upon submission and before peer-review. There can be important differences between the submitted version and the official published version of record.

People interested in the research are advised to contact the author for the final version of the publication, or visit the DOI to the publisher's website.

- The final author version and the galley proof are versions of the publication after peer review.

- The final published version features the final layout of the paper including the volume, issue and page numbers.

Link to publication

\footnotetext{
General rights rights.

- You may freely distribute the URL identifying the publication in the public portal. please follow below link for the End User Agreement:

www.umlib.nl/taverne-license

Take down policy

If you believe that this document breaches copyright please contact us at:

repository@maastrichtuniversity.nl

providing details and we will investigate your claim.
}

Copyright and moral rights for the publications made accessible in the public portal are retained by the authors and/or other copyright owners and it is a condition of accessing publications that users recognise and abide by the legal requirements associated with these

- Users may download and print one copy of any publication from the public portal for the purpose of private study or research.

- You may not further distribute the material or use it for any profit-making activity or commercial gain

If the publication is distributed under the terms of Article $25 \mathrm{fa}$ of the Dutch Copyright Act, indicated by the "Taverne" license above, 
Shared temporal cognitions as substitute for temporal leadership: An analysis of their effects on temporal conflict and team performance

Catarina Marques Santos ${ }^{\mathrm{a}}{ }^{1}$, Ana Margarida Passos $^{\mathrm{b}}$, Sjir Uitdewilligen ${ }^{\mathrm{c}}$, \& Annika Nübold $^{\mathrm{d}}$

${ }^{a}$ Instituto Universitário de Lisboa - ISCTE-IUL, Business Research Unit - BRU-IUL. Avenida das Forças Armadas, Edificio ISCTE, BRU-IUL, 1649-026 Lisboa, Portugal. E-mail: catarina_marques_santos@iscte.pt.

Telephone: +351210464019

${ }^{\mathrm{b}}$ Instituto Universitário de Lisboa - ISCTE-IUL, Business Research Unit - BRU-IUL. Avenida das Forças Armadas, Edificio ISCTE, BRU-IUL, 1649-026 Lisboa, Portugal. E-mail: ana.passos@iscte.pt

${ }^{c}$ Maastricht University, Department of Work and Social Psychology. Faculty of Psychology and Neuroscience, Maastricht University.

Universiteitssingel 5, Maastricht, 6229 ES, Netherlands.

E-mail: sjir.uitdewilligen@maastrichtuniversity.nl

${ }^{\mathrm{d}}$ Maastricht University, Department of Work and Social Psychology. Faculty of Psychology and Neuroscience, Maastricht University.

Universiteitssingel 5, Maastricht, 6229 ES, Netherlands.

E-mail: a.nubold@maastrichtuniversity.nl

${ }^{1}$ Correspondence concerning this article at all stages of refereeing, publication, and postpublication should be addressed to Catarina Marques Santos.

Acknowledgments: This work was supported by the Portuguese Foundation for Science and Technology (FCT) under Grant SFRH/BD/79292/2011 awarded to Catarina Marques Santos. 
Shared temporal cognitions as substitute for temporal leadership: An analysis of their effects on temporal conflict and team performance

Due to changing organizational demands, team leaders increasingly need to engage in temporal leadership behaviors in order to coordinate team members' efforts, avoid time related conflicts and ensure that teams perform well. Simultaneously, temporal conflicts and team performance are impacted by team members' shared temporal cognitions. In this study, we investigate the effect of temporal leadership and shared temporal cognitions on team performance via temporal conflict and test whether the impact of temporal leadership on temporal conflict may be substituted by shared temporal cognitions. Our study was conducted in a management simulation involving 142 teams working on a task over 5 weeks. Results suggest that temporal conflict mediates the relationship between temporal leadership and team performance as well as between shared temporal cognitions and team performance. Further, we found support for the idea that shared temporal cognitions function as a substitute of temporal leadership for reducing temporal conflict in teams.

Keywords: temporal leadership, shared temporal cognitions, temporal conflict, team performance, substitute for leadership. 
Over the last decades, organizations have faced a number of changes that pose novel challenges for teams in temporally integrating and coordinating their work processes. As the organizational contexts in which teams operate have become increasingly competitive, teams often have to work under tight deadlines while managing multiple projects at the same time (Gevers, van Eerde, \& Rutte, 2006; Waller, Conte, Gibson, \& Carpenter, 2001). As a result of these challenges, disagreement among team members on temporal issues or ambiguity over the temporal coordination of actions may arise and create tension and dissatisfaction among members, accumulating in temporal conflict (Jansen \& Kristof-Brown, 2005; Mohammed \& Nadkarni, 2011; Standifer et al., 2015). Temporal conflict refers to intragroup disputes about time, the duration of a task, and the length of time the team should spend on a specific task or goal (Gevers \& Petters, 2009; Mohammed \& Nadkarni, 2011). Previous research has demonstrated that temporal conflict is detrimental to a team's ability to attain high quality outputs in time (Mohammed \& Nadkarni, 2011; Standifer et al., 2015). Thus, in order to ensure that teams perform well, temporal conflict in teams needs to be minimized (Cataldo \& Herbsleb, 2013; Schmidt, Bienvenu, Fitzpatrick, \& Amazeen, 1998; Standifer et al., 2015). In order to avoid conflict over temporal issues in teams, such as meeting times and deadlines, it has become increasingly important to manage the time available to the team and its members. In the present study we propose two different solutions for avoiding or minimizing temporal conflict in teams, namely, temporal leadership and teams' shared temporal cognitions. Importantly, those two concepts represent different coordination mechanisms, an explicit one (temporal leadership) and an implicit one (shared temporal cognitions), both allowing team members to manage their interdependencies, avoiding conflict, and increasing performance (Rico, Sánchez-Manzanares, Gil, \& Gibson, 2008).

Temporal leadership refers to "leader behaviors that aid in structuring, coordinating, and managing the pacing of task accomplishment in a team" (Mohammed \& Nadkarni, 2011, 
p. 492). Temporal leadership is related to the functional leadership approach that postulates that leadership should aim to fulfill the team's needs in order to promote team effectiveness (Zaccaro, Rittman, \& Marks, 2001). Mohammed and Nadkarni (2011) operationalized the concept of temporal leadership showing that when team leaders employ strong temporal leadership behaviors they are able to reduce the problems and/or enlarge the benefits of diversity in time urgency (feeling chronically hurried and worried about the passage of time) and pacing style (people's preference for the allocation of time to accomplish tasks under deadlines). When team leaders employ strong temporal behaviors, such as allocation of temporal resources, definition of clear schedules and deadlines, and synchronization of activities, they create temporal synergies and reduce the problems related to time urgency diversity. In addition, strong temporal leadership behaviors convert pacing style diversity into a constructive team experience, avoiding team performance breakdowns (Mohammed \& Nadkarni, 2011). In sum, strong temporal leadership “dynamically adjusts individual work cycles and coordinates a team so that work is finished on time" (Mohammed \& Nadkarni, 2011, p. 494).

An alternative, but implicit solution for constraining temporal conflict and ensuring high team performance, is the development of shared temporal cognitions (Gevers et al., 2006; Mohammed \& Nadkarni, 2014; Standifer et al., 2015). Shared temporal cognitions represent a team's shared ideas with regard to "the temporal aspects of a specific group task, such as the importance of meeting the deadline, (sub)task completion times, and the appropriate timing and pacing of task activities" (Gevers et al., 2006, p. 54). When team members have similar perspectives about deadlines and there is little ambiguity about the timing of actions, this is likely to result in high temporal synchronization and low levels of temporal conflict among members. A number of studies have shown the importance of shared cognitions for facilitating the coordination of actions among team members and team 
performance (e.g., DeChurch \& Mesmer-Magnus, 2010; Mathieu, Heffner, Goodwin, Salas, \& Cannon-Bowers, 2000; Santos \& Passos, 2013; Uitdewilligen, Waller, \& Pitariu, 2013).

Recently, team researchers have called for studies that consider the interplay between implicit and explicit coordination mechanisms in order to reveal potential interaction effects (like substitution and complementation) on team performance (Espinosa, Lerch, \& Kraut, 2004; Rico et al., 2008). Specifically, it has been suggested that implicit coordination mechanisms (like teams' shared cognitions) may substitute explicit mechanisms during team interaction (like temporal leadership), particularly when teams are under time pressure (Espinosa et al., 2004). This idea is also in line with substitutes for leadership theory, suggesting that followers' knowledge and understanding may make leadership redundant (Dionne, Yammarino, Howell, \& Villa, 2005; Kerr \& Jermier, 1978). When team members have strong shared temporal cognitions as an internal resource, they do not need their leader to employ strong temporal leadership as they already have strong shared ideas for pacing, deadlines, and the alignment of task activities, and decreased temporal ambiguity. This renders the need for an external source of structuring temporal aspects (i.e., temporal leadership behaviors) less important for the team members.

In the present study we examine the mediating mechanism of temporal conflict in the relationship of temporal leadership (Hypothesis 1) and shared temporal cognitions (Hypothesis 2) on team performance. Further, as past research suggests (Nübold, Muck, \& Maier, 2013; Podsakoff, MacKenzie, \& Bommer, 1996), a substitution effect is best tested when researchers "examine whether the substitutes variables moderate relationships between leader behavior and subordinate criterion variables" (Podsakoff et al., 1996, p. 380). Therefore, we analyze the moderating influence of shared temporal cognitions on the relationship between temporal leadership and team performance (Hypothesis 3). Thus, we analyze whether shared temporal cognitions may function as a substitute for temporal 
leadership in avoiding temporal conflict. Finally, we analyze the interaction effect of temporal leadership and shared temporal cognitions on performance via temporal conflict with a mediated moderation model (Hypothesis 4).

The contributions of this paper are twofold. First, our study contributes to leadership theory in two ways: By focusing on the temporal aspects of leader behavior and incorporating temporality into a leadership construct (Mohammed \& Alipour, 2014), we account for the changing organizational demands and the increasing need to further understand how temporal aspects impact organizational functioning. This may prove especially important as leadership research has largely failed to integrate time (in terms of content) in conceptualizations of leadership (e.g., Van der Erve, 2004), although leaders play a key role in helping the team to be temporally coordinated and achieve high levels of performance. In addition, by investigating shared temporal cognitions as a boundary condition of leadership behavior, we aim to identify a new substitute for leadership in minimizing temporal conflict in the specific context of team cognition and team functioning.

Second, our study contributes to team research in two ways: By investigating the joint effect of teams' external resources - temporal leadership - and teams' internal resources shared temporal cognitions - we show how an implicit coordination mechanism may substitute an explicit coordination mechanism when reducing temporal conflict in teams and improving team performance. To date, no study has investigated the interplay of explicit and implicit coordination mechanisms and their joint effect on temporal conflict and team performance. Importantly, the power of shared temporal cognitions to substitute for temporal leadership also implies that both resources may compensate for the lack of the other, offering valuable implications for management and team practice. In addition, and similar to the incorporation of temporality in leadership conceptualizations, by focusing on the temporal aspects of team functioning (shared temporal cognition and temporal conflict), we advance 
scholarly understanding of temporal resources and challenges for teams and follow the call for more research on a highly neglected issue in team research (Halbesleben, Novicevic, Harvey, \& Buckley, 2003; Kozlowski \& Bell, 2003).

In sum, as effective time management is one of the most challenging aspects in today's business world (e.g., Clemens \& Dalrymple, 2005), our aim to focus on time related aspects in the interplay of leadership behavior and team cognition provides researchers and practitioners with information and strategies that may help them to synchronize team members' actions, avoid conflict over temporal issues, and to attain high levels of performance.

\section{Temporal Leadership, Temporal Conflict, and Team Performance}

Temporal leadership embodies scheduling of activities, synchronization of activities, and allocation of temporal resources to task accomplishment (Mohammed \& Nadkarni, 2011). Although temporal leadership captures the task-oriented leader behaviors focused on temporality, temporal leadership is distinct from task-focused leadership (Mohammed \& Nadkarni, 2011). Task-focused leadership refers to behaviors that aim to facilitate the understanding of task requirements, the operating procedures, and the task information acquisition (Burke et al., 2006). Those behaviors involve the standardization of task procedures, the definition of performance standards, as well as the establishment of welldefined task roles, objectives, and communication patterns (Casimir, 2001; Fleishman, 1995; Tabernero, Chambel, Curral, \& Arana, 2009). Thus, task-oriented leaders are focused on the tasks that need to be accomplished to achieve clearly defined goals and performance standards (Casimir, 2001; Burke et al., 2006; Fleishman, 1995). In contrast, temporal leadership refers to behaviors like reminding team members of important deadlines, prioritizing tasks and allocating time to each task, and urging team members to finish 
subtasks on time. Thus, temporal leadership behaviors specifically refer to the temporal aspects of the task (Mohammed \& Nadkarni, 2011).

The concept of temporal leadership emerged from the need to combine temporal activities and team leadership, due to the fact that team leaders increasingly faced temporal challenges, such as managing multiple time frames, deciding how fast the team should act, synchronizing team members' actions, and matching the pace of the team with the environment in which it operates (Ancona, Goodman, Lawrence, \& Tushman, 2001; Halbesleben et al., 2003; Mohammed \& Nadkarni, 2011). Team leaders play a crucial role in ensuring that team members' actions are aligned and coordinated so that they can accomplish team goals on time (Murase, Carter, DeChurch, \& Marks, 2014). Team leaders not only need to provide guidance and temporal information, but they also need to ensure that all members understand when tasks should be completed, when the outputs need to be delivered to the client, and when important deadlines are set. Thus, leaders should urge members to finish subtasks on time and verify whether they are doing what they are supposed to be doing and whether they are meeting their deadlines (Gevers et al., 2006; Mohammed \& Nadkarni, 2011).

Temporal leadership has been shown to have a positive influence on team performance (Maruping, Venkatesh, Thatcher, \& Patel, 2015; Mohammed \& Nadkarni, 2011). When team leaders understand the pertinent temporal issues of their task environments, they can translate these into clear guidelines for their team members and they can develop an integrated and flexible approach for managing the team's temporal challenges and resources (Ancona et al., 2001; Mohammed \& Nadkarni, 2011). Consequently, when team leaders provide temporal guidance to their teams, they help team members to effectively perform (Ancona et al., 2001). Temporal leadership helps team members to align the rhythm of their activities with internal and external deadlines, to coordinate the timing of their 
actions, and to accomplish the task efficiently while meeting deadlines (Mohammed \& Nadkarni, 2011; Waller et al., 2001). Further, temporal leadership helps team members to take advantage of the positive effects of intermediate levels of time pressure because team members view time pressure as a motivator, and define their plan of action in a way that is aligned with their time constraints (Maruping et al., 2015). Thus, temporal leadership behaviors help team members to plan their work, manage their time, and achieve high levels of performance (Mohammed \& Nadkarni, 2011).

However, over the team lifecycle obstacles may arise that may hinder the team's performance. Temporal conflict is one of those obstacles. The notion of temporal conflict was recently introduced by Yang (2009) as a variation of process conflict (Mohammed, Hamilton \& Lim, 2009; Standifer et al., 2015). Process conflict refers to disagreements among team members about the way the task should be accomplished, the progress of those tasks, and who is responsible for each task (Jehn, 1997). Temporal conflict is related to the temporal aspects of process conflict and refers to intragroup disputes about time, the duration of a task, and the length of time the team should spend on a specific task or goal (Gevers \& Petters, 2009; Mohammed, Ferzandi, \& Hamilton, 2010). In increasingly competitive organizational contexts where teams need to work together on tight deadlines over periods of weeks or months, it is particularly important to understand how temporal conflict may be avoided. Findings about temporal conflict suggest that it increases team members' frustration, leads to ambiguity about the temporal aspects of the work, and disrupts coordination. Thus, when teams are involved in conflict situations and are not temporally coordinated, team performance is negatively affected (Gevers \& Petters, 2009; Santos, Uitdewilligen, \& Passos, 2015a; Standifer et al., 2015).

Given that temporal conflict may disrupt team performance, temporal leadership behaviors that may reduce temporal conflict among team members are particularly important. 
The synchronizing of the team activities is likely to reduce the level of temporal conflict that teams experience because it helps to regulate the tasks' flow, to improve coordination, and to align the pace at which team members work to complete individual and team tasks (Bartel \& Milliken, 2004; Mohammed \& Nadkarni, 2011). Further, when team leaders engage in temporal behaviors they schedule the team members' activities and allocate the temporal resources of the team (Mohammed \& Nadkarni, 2011). Clear schedules and allocation of temporal resources are likely to reduce ambiguity about when tasks should be accomplished, minimize delays in meeting deadlines, and avoid disagreements about how the team should pace the task activities. Further, clear schedules and allocation of temporal resources help team members to understand how much time they should spend on each task in order to meet the deadlines (Bartel \& Milliken, 2004; Mohammed \& Nadkarni, 2011; Standifer et al., 2015).

In sum, when team leaders employ temporal behaviors, teams experience low levels of temporal conflict, thus, helping them to achieve high levels of performance.

Hypothesis 1: Temporal conflict mediates the relationship between temporal leadership and team performance.

\section{Shared Temporal Cognitions, Temporal Conflict, and Team Performance}

Shared temporal cognitions refer to a shared understanding among the team members of the temporal aspects of task execution (Gevers et al., 2006). Team members that share temporal cognitions have similar interpretations, expectations and preferences about time and deadlines, and are able to interpret temporal cues in an accurate way (Gevers et al., 2006; Standifer et al., 2015). Thus, as team members think in a similar way about the temporal aspects of work, they are able to accomplish tasks on time and achieve temporal synchronization (Bartel \& Milliken, 2004; Gevers et al., 2006). 
Positive relations have been reported between teams' shared temporal cognitions and performance (Gevers et al., 2006; Mohammed \& Nadkarni, 2014). Gevers and colleagues (2006) examined whether teams that have shared temporal cognitions are better able to meet deadlines than teams that have dissimilar temporal cognitions. They found that particularly teams that work early on the task (long before the deadline), benefit from having shared temporal cognitions (Gevers et al., 2006). Recently, Mohammed and Nadkarni (2014) investigated the moderating role of shared temporal cognitions in the relationship between polychronicity diversity (i.e., a preference for engaging in several tasks at the same time; Bluedorn, Kalliath, Strube, \& Martin, 1999) and team performance. They found that shared temporal cognitions attenuate the negative effects of polychronicity diversity on team performance. In addition, they found a strong positive main effect of shared temporal cognitions on performance.

As described above, empirical findings have shown that temporal conflict has a negative effect on performance (Santos et al., 2015a; Standifer et al., 2015). As teams disagree about the length of time they should spend on a task and the duration of a task, ambiguity about temporal aspects emerges within the team (Gevers \& Petters, 2009). The ambiguity disrupts temporal coordination so that team members are not able to work on the task and accomplish the goals, thus, negatively affecting performance.

Similar to the proposed effect for temporal leadership, we argue that shared temporal cognitions are also able to diminish the level of temporal conflict because temporal cognitions function as temporal norms - informal rules that help teams to regulate members' behaviors related to temporal issues, such as deadlines and delays (Janicik \& Bartel, 2003). Research on team conflict shows that whereas converging norms lead to harmony, divergence in norms is likely to result in interpersonal tension and disagreement among team members (Jehn \& Mannix, 2001). When team members perceive deadlines differently they may 
experience delays in information exchange, which can provoke anger and frustration (Guenter, van Emmerik, \& Schreurs, 2014). In contrast, when expectations and preferences regarding temporal aspects are aligned among team members (i.e., when team members have shared temporal cognitions), they are able to synchronize their actions and manage the available time efficiently (Janicik \& Bartel, 2003), thus, fostering high levels of team performance.

In sum, when teams share cognitions about the temporal issues they face, they will experience low levels of temporal conflict, thereby increasing their performance (Bartel \& Milliken, 2004; Gevers et al., 2006; Standifer et al., 2015).

Hypothesis 2: Temporal conflict mediates the relationship between shared temporal cognitions and team performance.

Temporal Leadership, Shared Temporal Cognitions, and Temporal Conflict

Substitutes for leadership theory suggests that specific individual, task and organizational characteristics may negate the leader's ability to positively or negatively influence subordinates' attitudes and effectiveness (Dionne, Yammarino, Atwater, \& James, 2002; Kerr \& Jermier, 1978). In this sense, substitutes are "aspects of the situation that cause intervening variables to be at optimal levels" (Yukl, 2010, p. 176) making leadership unneeded as it is not the only source of influence on individuals (Dionne et al., 2005). Employee characteristics that may function as a substitute for leadership include subordinate training or ability, aspects that directly influence subordinates' performance, regardless of leadership behavior (Dionne et al., 2002; Kerr \& Jermier, 1978). The idea that followers' competence and knowledge may function as a substitute for leadership has also been supported by empirical findings. Podsakoff and colleagues (1996) have shown for example that subordinates' positive perception of their ability, experience, training, and knowledge diminishes the beneficial effect of transformational leadership on role clarity. Further, De 
Vries, Roe, and Taillieu (2002) showed that a low need for leadership (derived from followers' evaluation of their skills and competencies) reduces the beneficial effect of leadership on followers' performance. Dionne and colleagues (2002) showed that when task variability decreases, leaders' contingent punishment is more strongly related to team effectiveness. Finally, Nübold and colleagues (2013) showed that transformational leadership behavior is not needed to promote followers' motivation and performance when followers' state core self-evaluations are high.

The idea of followers' knowledge and competence as a substitute for leadership can be easily applied to the context of temporal leadership and to teams that perform specific tasks within an environment characterized by tight deadlines and time pressure (Dionne et al., 2002). The temporal guidance team members need for mutually adjusting their expectations and synchronizing their actions in order to experience little temporal conflict may be provided externally by temporal leadership but it may also be derived internally, from within the team itself, by the team's shared temporal cognitions. When team members already have the internal resources in the form of knowledge on effective temporal coordination, they do not need an additional external resource providing them with temporal guidance (Rico et al., 2008). In other words, shared temporal cognitions may function as a substitute for temporal leadership and may represent an alternative route to low temporal conflict and increased team performance.

Knowledge on a team's (temporal) competence that may influence leadership effectiveness may help leaders to use temporal leadership behaviors more efficiently, that is, only in situations in which teams are truly in need of it to reduce temporal conflict and enhance team performance. In the case where team members already have high shared temporal cognitions, they are not in need of the leader's temporal guidance and supervision (Dionne et al., 2005). When team members have shared temporal cognitions, this helps them 
to anticipate what other team members need and what they will do, which prevents friction due to unmet expectations (Guenter et al., 2014; Rico et al., 2008). Team members make sense of these temporal issues themselves and negotiate norms and rules in order to avoid misunderstandings and conflicts.

In contrast, when team members' shared temporal cognitions are weak, they may specifically benefit from the guidance of a leader with regard to temporal issues. In this case, leaders' behaviors, such as providing clear indications on how time should be spent, when deadlines are due, when meetings take place, and what is expected from the members, may be a valuable external support that diminishes a team's temporal conflicts. The leaders make sense of the pertinent issues in the team's temporal environment and provide the team members with a clear temporal structure of when team members should do what and what they can expect from each other and in their environment (Zaccaro et al., 2001).

Interestingly, as temporal leadership and shared temporal cognitions may represent different mechanisms that have the same beneficial effect on temporal conflict, they are also able to compensate for the lack of the other. When team leaders employ temporal leadership behaviors, the leaders ensure that all the members are temporally aligned, agree on the task strategies they need to follow, and effectively allocate their temporal resources to their tasks (Mohammed \& Nadkarni, 2011), thus being able to compensate for the lack of teams' shared temporal cognitions. Conversely, shared temporal cognitions are vital to reduce the level of temporal conflict in situations of weak temporal leadership. When team leaders employ few temporal leadership behaviors, shared temporal cognitions are particularly important because they help team members to establish temporal norms. So, shared temporal cognitions work as an implicit coordination mechanism that may compensate for the lack of temporal leadership behaviors in containing temporal conflict.

In sum, temporal leadership and shared temporal cognitions function as explicit and 
implicit temporal coordination mechanisms that both may reduce the level of temporal conflict in teams. We propose that when teams share strong temporal cognitions, they do not need the guidance through temporal leadership in order to experience low levels of temporal conflict, thus, rendering shared temporal cognitions a substitute for leadership.

\section{Hypothesis 3: Shared temporal cognitions moderate the relationship between} temporal leadership and temporal conflict in such a way that the effect of temporal leadership on temporal conflict is weaker when shared temporal cognitions are high.

Finally, temporal leadership may have a differential effect on team performance via temporal conflict depending on the level of shared temporal cognitions (low vs. high). With low shared temporal cognitions, temporal leadership reduces the level of temporal conflict and, as a consequence, promotes team performance, while with high shared temporal cognitions there is no significant effect of temporal leadership on temporal conflict and, in turn, performance. The distinct effect of temporal leadership on team performance via temporal conflict depending on shared temporal cognitions again demonstrates the role of shared temporal cognitions as a substitute for temporal leadership. The research model is represented in Figure 1.

Hypothesis 4: The joint effect of temporal leadership and shared temporal cognitions on team performance is mediated by temporal conflict.

\section{- INSERT FIGURE 1 HERE -}

\section{Method}

\section{Participants}

A total of 142 teams (650 individuals) participated in this study. All teams were enrolled in a national management and strategy simulation over a 5-week period. The teams were composed of company workers $(46.0 \%)$, university students $(38.9 \%)$, or both (mixed teams) $(15.1 \%)$. Team sizes ranged from three to five members, with an average of 4.68 (SD 
$=.59)$. The majority of teams consisted of five persons (74.5\%). The average age was 29 years $(S D=8.44)$ and $65.8 \%$ of the participants were male.

\section{Simulation}

Data were collected from the participants of a national management and strategy simulation. During the simulation each teams run a fictitious company, with the objective of getting the highest company share price on the simulated stock exchange. The simulation lasted five weeks. Teams managed the company by making decisions about marketing, production, personnel, purchasing, and finance. Each team had a leader chosen by the team members when they enrolled for the simulation. The program analyzed and compared the decisions made by the competing teams and calculated the share price of each enterprise and the ranking of the teams. Then, the program produced a management report for each team, showing detailed financial results.

Time and time management were critical elements of the task the teams faced in the simulation. Participants of the simulation performed under high levels of time pressure. Every week teams needed to make decisions, analyze a large amount of information related to various areas of expertise, and coordinate their efforts efficiently to make the best decisions and submit them at a pre-scheduled moment. The simulation had very rigid weekly deadlines after which teams were not able anymore to submit their decision.

\section{Procedure}

We collected data at three different time moments. Team members answered online questionnaires through a link sent to the members by e-mail at two different time moments. Participants responded to the questionnaires in week 3 and week 4 before receiving feedback about their decisions. Shared temporal cognitions were measured in the third week of the simulation. Temporal leadership and temporal conflict were measured in the fourth week of the simulation. Performance was measured at the end of the simulation after the fifth week. 
Both performance and the composition variables (used as control variables) were provided by the company responsible for the simulation. Collecting data at different time moments reinforces causality inferences (Mathieu \& Taylor, 2006) and reduces common-method variance (Brannick, Chan, Conway, Lance, \& Spector, 2010; Spector, 2006).

\section{Measures}

\section{Temporal leadership.}

Seven items from the study by Mohammed and Nadkarni (2011) were used and adapted for this research context. On a 7-point scale $(1=$ never $; 7=$ always $)$, participants (excluding the team leader) indicated how often the team leader demonstrated specific behaviors (e.g., "To what extent is your team leader effective in coordinating the team to meet goals and deadlines?"). The scale revealed good reliability $(\alpha=.92)$.

\section{Shared temporal cognitions.}

Shared temporal cognitions were assessed with four items from the study by Gevers and colleagues (2006). On a 7-point scale $(1=$ totally disagree $;=$ totally agree $)$, the participants rated the extent to which they agreed with each sentence (e.g., "In my team, we have similar ideas about the time it takes to perform certain tasks"). The scale revealed good reliability $(\alpha=.93)$.

\section{Temporal conflict.}

Temporal conflict was measured through a modified three-item scale by Yang (2009) based on the original process conflict scale developed by Jehn (1997) and Shah and Jehn (1993). On a 7-point scale $(1=$ never; $7=$ always $)$, the participants indicated how often each behavior occurred in their team: 1) "How often are there disagreements about how long to spend on specific tasks in your team?"; 2) "How often are there disagreements about time allocation in your work team (how much time to spend on tasks)?"; 3) "How often are there disagreements about how you should pace task activities in your team?". The scale revealed 
good reliability $(\alpha=.92)$.

\section{Team performance.}

Team performance was operationalized through the share price at the end of the simulation. The share price comprehensively captures the quality of the team decisions as it is a function of the appropriateness of the teams' decisions given the specific context in which these decisions were made. Share price given in Euros, was automatically calculated and provided by the simulation and was the measure on which teams were evaluated. In the beginning of the simulation, all the companies that the teams run had the same share price: 1 Euro. The companies' share price changed over the simulation and the share price differed from one company to another, according to the teams' weekly decisions. Share price is a complex outcome measure that combines the decisions on the distinct topics on which team members need to make decisions (e.g., production, finance, and marketing) and thereby captures the combined effort of the team as a whole.

\section{Control variables.}

We included team size, task experience, team composition, as well as gender and age composition of the team as control variables in our analyses. We controlled for team size (number of team members) because it can impact a team's ability to develop team cognition, and learning processes (Bunderson \& Sutcliffe, 2003; Wheelan, 2009). We controlled for task experience (participation in previous editions of the simulation) as this may impact team performance (Amason \& Mooney, 1999; Passos \& Caetano, 2005). We also controlled for team composition (company workers, university students, and mixed) because it may impact performance as well (Bell, Villado, Lukasik, Belau, \& Briggs, 2010; Rico, SánchezManzanares, Antino, \& Lau, 2012). The categorical variable team composition was transformed into two dummy variables ('students' and 'mixed'), using company workers as a baseline, since they were the most common teams in the competition. Finally, we also 
controlled for gender (male percentage within the team) and age composition (mean age of the members in a team) as it can impact performance (Apesteguia, Azmat, \& Iriberri, 2012; LePine, Hollenbeck, Ilgen, Colquitt, \& Ellis, 2002).

\section{Confirmatory factor analysis}

As shared temporal cognitions, temporal leadership, and temporal conflict all refer to temporal aspects, we conducted a first-order and a second-order confirmatory factor analysis (CFA) in Mplus using the maximum likelihood estimation method to distinguish the three constructs (Muthén \& Muthén, 2012). The first-order CFA resulted in an acceptable, although not perfect model-fit: $\chi^{2}{ }_{(62)}=467.66, p<.001 ; \mathrm{AIC}=15253.57 ; \mathrm{BIC}=15433.89$; $\mathrm{CFI}=.92 ; \mathrm{SRMR}=.06(\mathrm{Hu} \&$ Bentler, 1999; Schreiber, Stage, King, Nora, \& Barlow, 2006). A review of the modification indexes revealed the presence of residual covariance between items 1 and 4 from the temporal leadership scale. Thus, we tested a second model in which we added the residual covariance between those two items (Byrne, 2012). The second model showed a good model fit: $\chi_{(61)}^{2}=218.94, p<.001 ;$ AIC $=15006.85 ; \mathrm{BIC}=15191.47$; $\mathrm{CFI}=.97 ; \mathrm{SRMR}=.05$. The difference in the $\chi^{2}$ values between the two models was statistically significant: $\Delta \chi^{2}=248.71, \Delta d f=1, p<.001$. The second model had a good fit to the data which was better than the one of the first model. However, a review of the modification index revealed the presence of a new residual covariance between items 4 and 5 from the temporal leadership scale. Therefore, we tested a third model in which we added the residual covariance between those two items, showing a good fit to the data: $\chi^{2}{ }_{(60)}=183.44, p$ $<.001 ; \mathrm{AIC}=14973.35 ; \mathrm{BIC}=15162.26 ; \mathrm{CFI}=.98 ; \mathrm{SRMR}=.05$. The difference in the $\chi^{2}$ values between the two models again was statistically significant: $\Delta \chi^{2}=35.51, \Delta d f=1, p<$ .001 . The third model fitted the data best of the three tested models.

Then, we conducted the second-order CFA constraining the variance of the secondorder factor to a value of 1.0 in order to freely estimate all second-order factor loadings 
(Byrne, 2012). The second-order model had a good model fit: $\chi^{2}(61)=211.43, p<.001$; AIC $=$ 14999.34; $\mathrm{BIC}=15183.96 ; \mathrm{CFI}=.97 ; \mathrm{SRMR}=.08$. The CFA results suggest that temporal leadership, shared temporal cognitions, and temporal conflict are distinct constructs.

\section{Results}

\section{Aggregation}

As the level of analysis in this study was the team level, the individual answers were aggregated to the team level (Costa et al., 2013). To justify aggregation, we computed $r_{\mathrm{wg}}$ (j), an estimate of within-group agreement designed for multiple-item scales. The widely-applied cut-off criterion for a good estimate of $r_{\mathrm{wg}(\mathrm{j})}$ refers to a mean value equal or above .70 (James, Demaree, \& Wolf, 1993). However, scholars have classified this criterion as "purely arbitrary" and have argued that the major limitation of $r_{\mathrm{wg}(\mathrm{j})}$ is "the ambiguity in choosing the most appropriate null response pattern (i.e., distribution)" (Biemann, Cole, \& Voelpel, 2012, p. 67). Therefore, in addition to the mean values we analyzed the degree of agreement in terms of two categories (a) lack of agreement or weak agreement and b) moderate, strong, or very strong agreement) for each variable. For temporal leadership, the $r_{\mathrm{wg}(\mathrm{j})}$ mean value is .72 , and $21.9 \%$ of the values indicate lack of agreement or weak agreement (ranging from .00 to .50 ), while $78.1 \%$ of the values indicate moderate, strong, or very strong agreement (ranging from .51 to 1.00) (Biemann et al., 2012). For shared temporal cognitions, the $r_{\mathrm{wg}(\mathrm{j})}$ mean value is .78 , and $9.8 \%$ of the values indicate lack of agreement or weak agreement, while $90.2 \%$ indicate moderate, strong, or very strong agreement. For temporal conflict, the $r_{\mathrm{wg}(\mathrm{j})}$ mean value is .74 , and $17.4 \%$ of the values indicate lack of agreement or weak agreement, while $82.6 \%$ indicate moderate, strong, or very strong agreement. As some teams showed lack of agreement or weak agreement, we conducted sensitivity analyses, testing our hypotheses with and without these teams in order to verify if the results have a similar pattern or are inconsistent (Biemann et al., 2012). The analyses without the teams that showed lack 
of agreement or weak agreement $(n=115$ teams) showed the same pattern of results as the analysis with those teams (i.e., the total sample; $n=142$ ). Therefore, we "can be more confident that the mixing of high and low agreement groups was not a serious enough problem" in our study (Biermann et al., 2012, p. 74).

We also computed intraclass correlation coefficients (ICC). Acceptable values of ICC(1) range between .05 and .20 . To be acceptable, the values of $\operatorname{ICC}(2)$ need to be superior to the ones of ICC(1) (Bliese, 2000). All the values were in accordance with the required criteria for temporal leadership $\left(\operatorname{ICC}(1)=.14 ; \operatorname{ICC}(2)=.43 ; F_{(141,440)}=1.74, p<.001\right)$, shared temporal cognitions $\left(\operatorname{ICC}(1)=.12 ; \operatorname{ICC}(2)=.38 ; F_{(141,510)}=1.62, p<.001\right)$ and temporal conflict $\left(\operatorname{ICC}(1)=.10 ; \operatorname{ICC}(2)=.33 ; F_{(141,442)}=1.49, p<.01\right)$.

\section{Hypotheses Testing}

Table 1 provides the means, standard deviations, and correlations for all variables at the team level. Significant positive correlations were found between temporal leadership, shared temporal cognitions, and performance. Significant negative correlations were found between temporal conflict and all the other variables. In all the analyses, task experience, team size, team composition, mean age of team members and gender composition of the team were entered as controls.

\section{- INSERT TABLE 1 HERE -}

We used the statistical software Mplus (Muthén \& Muthén, 2012) for testing our hypotheses. Similar to prior studies (Nübold et al., 2013; Zhou, 2003), we used one-tailed significance tests (and 95\% confidence intervals) for all analysis because the direction of our hypotheses was specified a priori. To analyze the mediation hypotheses we used Mplus to create 5000 bootstrap samples and use $95 \%$ confidence intervals (CI) (Preacher \& Hayes, 2008). Hypothesis 1 proposes that temporal conflict mediates the relationship between temporal leadership and team performance. The model presented a good fit (Hu \& Bentler, 
1999; Schreiber et al., 2006): $\chi^{2}{ }_{(1)}=1.25, p>.05 ; \mathrm{CFI}=0.99 ; \mathrm{SRMR}=.01$. The unstandardized parameter estimate showed that temporal conflict significantly mediated the relationship of temporal leadership with team performance $(.03[\mathrm{CI}=.01, .06], p<.05)$, supporting Hypothesis 1.

Hypothesis 2 proposes that temporal conflict mediates the relationship between shared temporal cognitions and team performance. The model also had a good fit: $\chi_{(1)}^{2}=0.54, p>$ $.05 ; \mathrm{CFI}=1.00 ; \mathrm{SRMR}=.01$. The unstandardized parameter estimate showed that temporal conflict mediated the relationship of shared temporal cognitions and team performance (.03 $[\mathrm{CI}=.01, .07], p<.05)$, supporting Hypothesis 2.

To test the moderation analysis as well as the mediated moderation analysis in one model, we performed a unified test in Mplus creating 5000 bootstrap samples and using 95\% confidence intervals (Preacher \& Hayes, 2008). Hypothesis 3 proposes a moderating effect of shared temporal cognitions on the relationship between temporal leadership and temporal conflict. We centered the independent variables and calculated the interaction term, following the procedure suggested by Aiken and West (1991). The model presented a good fit (Hu \& Bentler, 1999; Schreiber et al., 2006): $\chi^{2}{ }_{(3)}=3.28, p>.05 ; \mathrm{CFI}=0.99 ; \mathrm{SRMR}=.02$.

The results show that team size and the mixed teams dummy significantly predicted temporal conflict $(B=.22, p<.05 ; B=-.40, p<.05$, respectively). Regarding the main effects, temporal leadership $(B=-.32, p<.001)$ and shared temporal cognitions $(B=-.23, p<$ .01) were both significantly negatively related to temporal conflict. The interaction effect between temporal leadership and shared temporal cognitions was significantly and positively related to temporal conflict $(B=.22, p<.01)$. The results indicate that $42 \%$ of the variance of temporal conflict was explained by the control variables, the main effects of temporal leadership and shared temporal conflict, and the interaction effect between these two variables (see Table 2). 
- INSERT TABLE 2 HERE -

As the interaction effect was significant, we graphed it following the procedure suggested by Aiken and West (1991) and Dawson (2013). Figure 2 shows the regression slopes for the effect of high and low shared temporal cognitions on temporal conflict under strong and weak temporal leadership (+/- $1 S D$ above and below the mean, respectively; Aiken \& West, 1991). When shared temporal cognitions were low, temporal leadership was significantly related to temporal conflict $(B=-.45, p<.001)$. This means that when team members have low shared temporal cognitions, they benefit from temporal leadership in terms of experiencing low levels of temporal conflict. In contrast, in situations of strong shared temporal cognitions, temporal leadership was not significantly related to temporal conflict $(B=-.18, p>.05)$. That is, teams who share strong temporal cognitions do not benefit from temporal leadership as their level of understanding of the temporal aspects in their team is already high. Thus, they were not in need of the temporal guidance of their leader. Thus, Hypothesis 3 was supported.

\section{- INSERT FIGURE 2 HERE -}

The mediated moderation results showed that the joint effect of temporal leadership and shared temporal cognitions on team performance mediated by temporal conflict was marginally significant $(-.02[-.04, .00], p=.07)$. As the mediated moderation was significant by tendency, we further analyzed this effect by performing a multiple group analysis following the suggestion by Hox (2012). In the multiple group analysis we tested whether the mediation effect of temporal conflict would differ between the teams that had weak shared temporal cognitions and those that had strong temporal cognitions. We created two groups for shared temporal cognitions (strong vs. weak), split on the median $(M d=5.59)$, and compared the mediation effects across these two groups (Fishbach, Friedman, \& Kruglanski, 2003; Hox, 2012; Iacobucci, Posavac, Kardes, Schneider, \& Popovich, 2015a). The results showed 
that for the group with weak shared temporal cognitions, temporal conflict mediated the effect of temporal leadership on performance $(.04[.01, .07], p<.01)$. In contrast, for the group with strong shared temporal cognitions, temporal conflict did not mediate the effect of temporal leadership on group performance $(-.00[-.02, .01], p>.05)$. We computed the Wald Test of Parameter Constraints to analyze if the difference between the mediation effects was significant (Hox, 2010). The results showed that the effects for the two groups significantly differed (Wald test $=4.47, d f=1, p<.05$ ). The use of median splits has been criticized by a number of scholars for producing Type I error and for the reduction in statistical power (McClelland, Lynch, Irwin, Spiller, \& Fitzsimons, 2015; Rucker, McShane, \& Preacher, 2015). Nevertheless, we can assume that the median split did not lead to Type I error or to misleading results because multicollinearity is absent in our data (Iacobucci et al., 2015a; Iacobucci, Posavac, Kardes, Schneider, \& Popovich, 2015b). There were no high correlations among predictor variables (i.e., the variance inflation factor (VIF) is lower than 2.5 and tolerance is higher than 0.1 ): Shared temporal cognitions as criterion variable: $\mathrm{VIF}=1.35$; tolerance $=0.74 ;$ temporal leadership as criterion variable: $\mathrm{VIF}=1.28 ;$ tolerance $=.78$; temporal conflict as criterion variable: $\mathrm{VIF}=0.81$; tolerance $=1.23$ (Allison, 1999 ; Wooldridge, 2013). Thus, Hypothesis 4 was supported.

\section{Discussion}

Our study provides two major findings that have important implications for researchers and practitioners. First, our study provides insight into the way temporal leadership and shared temporal cognitions diminish the level of temporal conflict and benefit team performance. Second, our findings suggest that shared temporal cognitions may be a substitute for temporal leadership regarding its role of reducing temporal conflict and improving team performance. High shared temporal cognitions work as an implicit coordination mechanism that helps team members to establish temporal norms, minimize 
temporal conflict, and achieve high levels of performance regardless of the leader's temporal behaviors. When shared temporal cognitions are low, however, temporal leadership may be an effective mean to support team members in gaining a shared understanding of temporal aspects in their team, thereby lowering temporal conflict and improving team performance.

Team leadership research has been criticized for neglecting the temporal aspects and needs of teams and organizations (Shamir, 2011; Van der Erve, 2004). Over the years, researchers have analyzed the relationship between a number of team leaders' characteristics or behaviors and outcomes (Shamir, 2011). However, researchers have failed to integrate time as content in team leadership constructs as well as to consider how the relationship between leadership inputs and outcomes are time dependent and may change over time (Shamir, 2011; Van der Erve, 2004). Although we did not account for the role of time in a longitudinal fashion (i.e., in terms of change patterns of our concepts), we incorporated temporality in terms of content into a leadership construct (Mohammed \& Alipour, 2014). Temporal leadership is particularly relevant for team research because it considers "the process by which leaders manage multiple time frames, synchronize member contributions, and coordinate work so that deadlines are met" (Mohammed \& Alipour, 2014, p. 178). Our findings contribute to temporal leadership research showing its effect in reducing temporal conflict and promoting team performance. In organizational environments where leaders face a number of temporal challenges, such as managing multiple projects at the same time, managing people that are often member of different teams, and managing virtual and geographically dispersed teams (Murase et al., 2014; Waller et al., 2001), leaders need to employ behaviors that help the team to be temporally coordinated and to perform well.

In a similar vein, Kozlowski and Bell (2003) stated that time is "perhaps the most neglected critical issue" in team research and theory (p. 364). Over the last years, significant progress has been made on research regarding the role of time-related aspects in teams 
leading to the emergence of a number of temporal constructs (e.g., Gevers et al., 2006; Mohammed \& Nadkarni, 2014; Mohammed et al., 2015; Santos, Uitdewilligen, \& Passos, 2015b; Standifer et al., 2015). However, researchers neither analyzed the joint effect of different temporal constructs on team processes and performance, nor investigated the mediating mechanism of a team process (temporal conflict) between temporal predictors (temporal leadership and shared temporal cognitions) and performance outcomes. Thus, our study contributes to the integration of temporality in team research by demonstrating that temporal leadership and shared temporal cognitions reduce the level of temporal conflict and promote performance. Interestingly, our findings show that shared temporal cognitions and temporal leadership may compensate for the lack of the other.

Researchers have also criticized the lack of integration of temporality in shared cognitive constructs (Mohammed, Tesler, \& Hamilton, 2012). Nevertheless, in the last years, researchers have made efforts to integrate temporality in shared cognitive constructs and they have conceptualized and analyzed different constructs, such as shared temporal cognitions (Gevers et al., 2006), temporal transactive memory systems (Mohammed \& Nadkarni, 2014), and temporal shared mental models (Mohammed et al., 2015; Santos et al., 2015b). In the present study we focus on shared temporal cognitions analyzing the mechanisms and boundary conditions of the effects of shared temporal cognitions on performance (Bluedorn \& Jaussi, 2008; Halbesleben et al., 2003; Waller et al., 2001). Our findings suggest that temporal conflict is an important mechanism explaining how shared temporal cognitions impact team performance. This provides evidence that there indeed is value in continuing to examine temporal conflict in future research as it functions as a very specific mechanism explaining the effects of shared temporal cognitions on team performance.

Finally, researchers have posited that we need to conduct studies that allow us to understand "the boundary conditions under which particular aspects of team leadership affect 
specific mechanisms" (DeChurch, Hiller, Murase, Doty, \& Salas, 2010, p. 1081). By looking at the joint effects of temporal leadership and shared temporal cognitions on temporal conflict and team performance we heeded these calls and provide new insights on substitutes for leadership (Kerr \& Jermier, 1978). Although there has been a growing number of studies identifying individual and task level variables as potential substitutes (e.g., Dionne et al., 2002; Kerr \& Jermier, 1978; Künzle, Zala-Mezö, Kolbe, Wacker, \& Grote, 2010; Nübold et al., 2013), knowledge on team-level factors that substitute for team leadership is still lacking. Researchers have analyzed the effects of various team leader behaviors on team processes and performance (e.g., Liu, Hu, Li, Wang, \& Lin, 2014; Murase et al., 2014; Zaccaro et al., 2001); however, researchers have not presented solutions that could ensure that teams function and perform well in situations of weak or no leadership. Our findings suggest that a specific internal coordination mechanism (shared temporal cognition) may substitute a specific kind of team leadership behavior (temporal leadership behavior).

Moreover, we show that shared temporal cognitions may substitute temporal leadership in reducing the level of temporal conflict as well as promoting team performance. Our findings suggest that teams do not need temporal leadership when shared temporal cognitions are high and that both temporal leadership and shared temporal cognitions can compensate for the lack of the other. When team members have shared temporal cognitions, they make sense of the similar thoughts they have about the best way to use their time, and about the time it takes to perform the tasks to negotiate norms and rules in order to avoid misunderstandings and conflicts. Team researchers have long been interested in the interplay between explicit and implicit mechanisms of coordination (Espinosa et al., 2004). Teams may apply explicit coordination mechanisms, such as planning and leadership, or they may depend on the implicit mechanisms of shared cognition to align and integrate their activities into a unified whole (Rico et al., 2008). Although theoretical work suggests that both explicit and 
implicit coordination mechanisms can be important for team functioning, research that combines both types of mechanisms is lacking.

As Dionne and colleagues (2005) suggested "important substitutes for leadership can and do exist for specific leadership behaviors without eliminating the need for all leadership behaviors" (p. 176). Shared temporal cognitions represent an effective mean to substitute for temporal leadership because both constructs focus on the temporal aspects of the task. Therefore, it seems likely that shared temporal cognitions do not function as a substitute for other leadership styles to the same extent. In addition, temporal leadership does not exclude the need for other leadership styles or functions. In fact, the combination of different behaviors or styles may be particularly beneficial for teams' functioning and performance. Both temporal and task-oriented leadership behaviors, for instance, may benefit team functioning and reduce both temporal and task conflict because leaders not only provide temporal guidance but also provide well-defined task roles, objectives and performance standards (Fleishman, 1995; Mohammed \& Nadkarni, 2011). Leader performance functions may also be beneficial for teams as they facilitate team cognitive, motivational, affective, and coordination processes and, in turn, team effectiveness (Zaccaro et al., 2001). Team leaders may employ the performance functions and suggest activities and solutions that are appropriate for the specific situation the team faces and in accordance with the deadlines and performance standards the team needs to meet.

\section{Practical Implications}

Our findings present a number of implications for organizational teams and, in particular, for team leaders. The results of our study contribute to the understanding of how leaders that employ temporal behaviors help the team to avoid disagreements about the temporal aspects of work and, in turn, promote high levels of performance. Leaders should be made aware of the importance of the scheduling, synchronization and prioritization of tasks 
and the allocation of time for each task. Team leaders can be trained how to communicate these aspects to team members and how to monitor them over time. These temporal behaviors help the team members to prioritize tasks and allocate the time to each task, to know and agree with each other on the deadlines, when they need to start and finish a task, and how much time they need to spend on each task. If the team is temporally coordinated, it is more likely to achieve high levels of performance. Temporal agreement and temporal coordination is particularly important, for instance when teams need to work under a lot of time pressure and meet very close deadlines and when team members work at multiple projects at the same time. In those situations, whenever possible, leaders may be assigned to a team based on his/her ability to employ temporal behaviors.

Our findings also help to understand how the understanding about the temporal aspects that team members share is important to reduce the level of temporal conflict and foster performance. From the beginning of the team lifecycle, team members should have the opportunity to discuss with each other the best way to use their time and to allocate the time available to the tasks they need to perform. A discussion about those topics helps the team to build a temporal shared knowledge and to agree on the temporal aspects of the work which, in turn, helps the team to successfully accomplish the tasks.

Finally, our results suggest that agreement on temporal issues and team performance is not only dependent on team leaders' behaviors. At different moments, team members or team leaders may be responsible for reducing the level of temporal conflict and promoting team performance. In situations where the assigned leader has no skills or competencies to help the team to avoid temporal conflicts and achieve high levels of performance, the team members may decide to discuss with each other the best way to prioritize tasks, to finish the tasks on time, or to coordinate the team to meet deadlines. If the team leader feels that he/she is not able to help the team and that the team is able to align and integrate the activities itself, 
he/she can ask the team members to discuss with each other the temporal aspects of work to ensure that the team is able to accomplish its goals. Thus, team members may help each other to provide guidance and temporal information and to verify whether the team is doing what it is supposed to be doing. In sum, strong shared temporal cognitions may compensate for the lack of high temporal leadership behaviors.

\section{Limitations and Directions for Future Research}

In the present study we focused on time as the content of several concepts. Although we stressed the added value our study brings for team and team leadership research, future studies should also focus on time as a dynamic process (i.e., in longitudinal studies) in order to understand the role of time on the different phenomena. It could be analyzed, for instance, whether the effect of temporal leadership on temporal conflict and performance depends on the specific phase the team is in. Future studies should combine the concept of time as integral part of the study concepts and time as a dynamic process inherent in the study design. Longitudinal designs should be used to track the changes in team functioning over the team lifecycle. Further, future research should explore questions about time in teams; particularly in teams for which time (pressure) is an essential building block for their emergence, such as rapid response or crisis management teams.

Our measurement at both the individual and team level showed some limitations. At the individual level, our data revealed the presence of residual covariance between items from the leadership scale, which refers to a measurement error in item responses (Byrne, 2012). Residual covariance may be related to social desirability of respondents or to a very high overlap in item content (Byrne, 2012). Future research should ensure that social desirability becomes less problematic, for instance, by increasing the motivation to provide honest responses.

At the team level, our data revealed that for about 10\% - 20\% of the teams (depending 
on the variable) the $r_{\mathrm{wg}(\mathrm{j})}$ were poor (>.50), indicating a lack of or weak agreement among team members. Nevertheless, most of the teams had moderate, strong, or very strong agreement, and the analyses without the teams that had a lack of agreement or weak agreement showed the same pattern of results as the analysis with those teams. Therefore, we recommend to adopt a similar approach in future research and conduct sensitivity analyses when the results reveal $r_{\mathrm{wg}(\mathrm{j})}$ with lack of or weak agreement. In this way, hypotheses can be tested with and without those teams that lack or only show weak agreement to verify whether the results have a similar or different pattern. Regarding the temporal leadership measure, it could be interesting for future research to analyze the dispersion in the evaluation team members make about their leader's temporal leadership behaviors (Boies \& Howell, 2006; Graen \& Uhl-Bien, 1995). According to LMX theory, "leaders do not treat all followers identically; rather, they develop different quality of relationships with followers" (Boies \& Howell, 2006, p. 246). Thus, team leaders may employ different temporal behaviors depending on characteristics of the team members. For instance, leaders may more actively engage in temporal leadership towards members they perceive to need more temporal guidance.

Further, future research should analyze the consequences and implications for those teams that have low agreement in these constructs. Team researchers have predominantly focused on similar perceptions team members have about team dynamics phenomena and have operationalized these in terms of the mean scores on these variables among the team members. However, multilevel theorists argue that dispersion is an inherent property of any group-level phenomenon and scholars should go beyond operationalization of mean levels and also include dispersion indices in order to fully understand how these phenomena impact team outcomes (De Jong, Van der Vegt, \& Molleman, 2007; Kozlowski \& Klein, 2000; Kozlowski \& Chao, 2012). 
Despite our approach to separate the different measurements in time, common-method variance may be a limitation (Siemsen, Roth, \& Oliveira, 2010). Some authors argue that common-method variance is not a problem and that the spurious causes of relationships among variables are related to the mixture of methods and constructs and not related to the methods themselves (Brannick et al., 2010). However, in order to limit concerns for common-method variance, in particular because we use perceptual measures answered by the same respondents, we measured the variables at different moments in time.

\section{Conclusion}

In increasingly complex, dynamic and time pressed organizational contexts, team leaders have a crucial role to play in providing team members with important tools to help them achieve high levels of performance within strict deadlines. Our study shows that team leader behaviors that focus on the temporal aspects of work help team members to reduce temporal conflict and achieve high levels of performance. Further, our findings suggest that team members' shared temporal cognitions function as a substitute for temporal leadership. That is, if shared temporal cognitions are high, there is no need for temporal leadership in order for teams to experience low levels of temporal conflict. This also implies that shared temporal cognitions can compensate for the lack of temporal leadership and vice versa in order to diminish temporal conflict in teams. 


\section{References}

Aiken, L., \& West, S. G. (1991). Multiple regression: Testing and interpreting interactions. Newbury Park, CA: SAGE.

Allison, P. D. (1999). Multiple Regression: A Primer. Thousand Oaks, CA: SAGE Publications.

Amason, A. C., \& Mooney, A. C. (1999). The effects of past performance on top management team conflict in strategic decision making. International Journal of Conflict Management, 10, 340-359. DOI:10.1108/eb022829

Ancona, D. G., Goodman, P. S., Lawrence, B. S., \& Tushman, M. L. (2001). Time: A new research lens. Academy of Management Review, 26, 645-663. DOI:

10.5465/AMR.2001.5393903

Apesteguia, J., Azmat, G., \& Iriberri, N. (2012). The impact of gender composition on team performance and decision making: Evidence from the field. Management Science, 58, 78-93. DOI: http://dx.doi.org/10.1287/mnsc.1110.1348

Bartel, C. A., \& Milliken, F. J. (2004). Perceptions of time in work groups: Do members develop shared cognitions about their temporal demands?. In S. Blount (Ed.). Research on Managing Groups and Teams: Time in Groups (Vol. 6) (pp.87-110). New York: Elsevier.

Bell, S. T., Villado, A. J., Lukasik, M. A., Belau, L., \& Briggs, A. L. (2010). Getting specific about demographic diversity variable and team performance relationships: A metaanalysis. Journal of Management, 37, 709-743. DOI: 10.1177/0149206310365001

Biemann, T., Cole, M. S., \& Voelpel, S. (2012). Within-group agreement: On the use (and misuse) of $r_{w g}$ and $r_{w g(j)}$ in leadership research and some best practice guidelines. The Leadership Quarterly, 23, 66-80. DOI: 10.1016/j.leaqua.2011.11.006

Bliese, P. D. (2000).Within-group agreement, non-independence, and reliability: 
Implications for data aggregation and analysis. In K. J. Klein \& S. W. J. Kozlowski (Eds.), Multilevel Theory, Research, and Methods in Organizations (pp. 349-381). San Francisco: Jossey-Bass.

Bluedorn, A. C. \& Jaussi, K. S. (2008). Leaders, followers, and time. The Leadership Quarterly, 19, 654-668. DOI:10.1016/j.leaqua.2008.09.006

Bluedorn, A.C., Kalliath, T.J., Strube, M.J. \& Martin, G.D. (1999). Polychronicity and the Inventory of Polychronic Values (IPV): The development of an instrument to measure a fundamental dimension of organizational culture. Journal of Managerial Psychology, 14, 205-230. DOI: http://dx.doi.org/10.1108/02683949910263747

Boies, K. \& Howell, J. M. (2006). Leader-member exchange in teams: An examination of the interaction between relationship differentiation and mean LMX in explaining teamlevel outcomes. The Leadership Quarterly, 17, 246-257. DOI:

10.1016/j.leaqua.2006.02.004

Brannick, M. T., Chan, D., Conway, J.M., Lance, C.E., \& Spector, P.E. (2010). What is method variance and how can we cope with it? A panel discussion. Organizational Research Methods, 13, 407-420. DOI: 10.1177/1094428109360993

Bunderson, J. S. \& Sutcliffe, K. M. (2003). Management team learning orientation and business unit performance. Journal of Applied Psychology, 88, 552-560. DOI:10.1037/0021-9010.88.3.552

Burke, C. S., Stagl, K., C., Klein, C., Goodwin, G. F., Salas, E., \& Halpin, S. M. (2006). What type of leadership behaviors is functional in teams? A meta-analysis. The Leadership Quarterly, 17, 288-307. DOI: 10.1016/j.leaqua.2006.02.007

Byrne, B. M. (2012). Structural Equation Modeling with Mplus: Basic concepts, applications, and programming. New York: Routledge.

Casimir, G. (2001). Combinative aspects of leadership style: The ordering and temporal 
spacing of leadership behaviors. The Leadership Quarterly, 12, 245-278. DOI: $10.1016 / \mathrm{S} 1048-9843(01) 00079-0$

Cataldo, M., \& Herbsleb, J. D. (2013). Coordination breakdowns and their impact on development productivity and software failures. IEEE Transactions on Software Engineering, 39, 343-360. DOI: 10.1109/TSE.2012.32

Clemens, J. K., \& Dalrymple, S. (2005). Time mastery: How temporal intelligence will make you a stronger, more effective leader. New York, NY: American Management Association.

Costa, P. L., Graça, A. M., Marques-Quinteiro, P., Santos, C. M., Caetano, A., \& Passos, A.M. (2013). Multilevel research in the field of Organizational Behavior: An empirical look at 10 years of theory and research. SAGE Open, 1-17. DOI:

$10.1177 / 2158244013498244$

Dawson, J. F. (2013). Moderation in management research: What, why, when and how. Journal of Business and Psychology, 29, 1-19. DOI: 10.1007/s10869-013-9308-7

DeChurch, L. A., \& Mesmer-Magnus, J. R. (2010). The cognitive underpinnings of effective teamwork: A meta-analysis. Journal of Applied Psychology, 95, 32-53. DOI: $10.1037 / \mathrm{a} 0017328$

DeChurch, L. A., Hiller, N. J., Murase, T., Doty, D., \& Salas, E. (2010). Leadership across levels: Levels of leaders and their levels of impact. The Leadership Quarterly, 21, 1069-1085. DOI: 10.1016/j.leaqua.2010.10.009

De Jong, S. B., Van der Vegt, G. S., \& Molleman, E. (2007). The relationships among asymmetry in task dependence, perceived helping behavior, and trust. Journal of Applied Psychology, 92, 1625-1637. DOI: http://dx.doi.org/10.1037/0021$\underline{9010.92 .6 .1625}$

De Vries, R.E., Roe, R.A., \& Taillieu, T.C.B. (2002). Need for Leadership as moderator of 
the relationship between leadership and individual outcomes. The Leadership Quarterly, 13, 121 - 137. DOI: http://dx.doi.org/10.1016/S1048-9843(02)00097-8

Dionne, S. D., Yammarino, F. J., Atwater, L. E., James, L. R. (2002). Neutralizing substitutes for leadership theory: Leadership effects and common-source bias. Journal of Applied Psychology, 87, 454-464. DOI: 10.1037//0021-9010.87.3.454

Dionne, S. D., Yammarino, F. J., Howell, J. P., \& Villa, J. (2005). Substitutes for leadership, or not. The Leadership Quarterly, 16, 169-193. DOI:10.1016/j.leaqua.2004.09.012

Espinosa, J.A., Lerch, F.J., \& Kraut, R.E. (2004). Explicit versus implicit coordination mechanisms and task dependencies: One size does not fit all. In E. Salas, \& S.M. Fiore (Eds.). Team cognition: Understanding the factors that drive process and performance (pp. 107-129). Washington, DC: American Psychological Association.

Fishbach, A., Friedman, R. S., \& Kruglanski, A. W. (2003). Leading us not unto temptation: Momentary allurements elicit overriding goal activation. Journal of Personality and Social Psychology, 84, 296-309. DOI: 10.1037/0022-3514.84.2.296

Fleishman, E. A. (1995). Consideration and structure: Another look at their role in leadership research. In F. Dansereau \& F. J. Yammarino (Eds.), Leadership: The multiple-level approaches (pp. 51-60). Stamford, CT: JAI.

Gevers, J. M. P., \& Petters, M. A. G. (2009). A pleasure working together? The effects of dissimilarity in team member conscientiousness on team temporal processes and individual satisfaction. Journal of Organizational Behavior, 30, 379-400. DOI: $10.1002 /$ job.544

Gevers, J. M. P., Rutte, C. G., \& van Eerde, W. (2006). Meeting deadlines in work groups: Implicit and explicit mechanisms. Applied Psychology: An International Review, 55, 52-72. DOI: 10.1111/j.1464-0597.2006.00228.x 
Graen, G. B., Uhl-Bien, M. (1995). Relationship-based approach to leadership: Development of Leader-Member Exchange (LMX) theory of leadership over 25 years: Applying a multi-level multi-domain perspective. Leadership Quarterly, 6, 219-247.

Guenter, H., Van Emmerik, I. J. H., \& Schreurs, B. (2014). The negative effects of delays in information exchange: Looking at workplace relationships from an affective events perspective. Human Resource Management Review, 24, 283-298.

DOI:10.1016/j.hrmr.2014.02.001

Halbesleben, J. R. B., Novicevic, M.M., Harvey, M. G., \& Buckley, R. (2003). Awareness of temporal complexity in leadership of creativity and innovation: A competency-based model. The Leadership Quarterly, 14, 433-454. DOI: 10.1016/S1048-9843(03)00046-8

Hox, J. J. (2010). Multilevel analysis: Techniques and applications. $2^{\text {nd }}$ edition. New York: Routledge.

Hox, J. J. (2012, March). Statistical Modeling in Mplus. 41th GESIS Spring Seminar: Topics in Social Science Data Analysis: Causality, Structural Equation Modeling with AMOS and Mplus. GESIS - Leibniz-Institute for the Social Sciences.

Hu, L., \& Bentler, P. M. (1999). Cut of criteria for fit indexes in covariance structure analysis: Conventional criteria versus new alternatives. Structural Equation Modeling, 6, 1-55. DOI: 10.1080/10705519909540118

Iacobucci, D., Posavac, S. S., Kardes, F. R., Schneider, M. J., \& Popovich, D. L. (2015a). Toward a more nuanced understanding of the statistical properties of a median split. Journal of Consumer Psychology, 25, 652-665. DOI: 10.1016/j.jcps.2014.12.002

Iacobucci, D., Posavac, S. S., Kardes, F. R., Schneider, M. J., \& Popovich, D. L. (2015b). The median split: Robust, refined, and revived. Journal of Consumer Psychology, 25, 690-704. DOI: 10.1016/j.jcps.2015.06.014 
James, L. R., Demaree, R. J., \& Wolf, G. (1993). $r_{w g}$ : An assessment of within group interrater agreement. Journal of Applied Psychology, 78, 306-309. DOI: http://dx.doi.org/10.1037/0021-9010.78.2.306

Janicik, G. A., \& Bartel, C. A. (2003). Talking about time: Effects of temporal planning and time awareness norms on group coordination and performance. Group Dynamics: Theory, Research, and Practice, 7, 122-134. DOI: 10.1037/1089-2699.7.2.122

Jansen, K. J. \& Kristof-Brown, A. L. (2005). Marching to the beat of a different drummer: Examining the impact of pacing congruence. Organizational Behavior and Human Decision Processes, 97, 93-105. DOI: 10.1016/j.obhdp.2005.03.005

Jehn, K. A., \& Mannix, E. A. (2001). The dynamic nature of conflict: A longitudinal study of intragroup conflict and group performance. Academy of Management Journal, 44, 238251. DOI: $10.2307 / 3069453$

Jehn, K.A. (1997). A qualitative analysis of conflict types and dimensions in organizational groups. Administrative Science Quarterly, 42, 530-557. DOI: 10.2307/2393737

Kerr, S. \& Jermier, J.M. (1978). Substitutes for leadership: Their meaning and measurement. Organizational Behavior and Human Performance, 22, 375-403. DOI: 10.1016/0030$5073(78) 90023-5$

Kozlowski, S. W. J. \& Bell, B. S. (2003). Work groups and teams in organizations. In W. C. Borman, D. R. Ilgen \& R. J. Klimoski (Eds.), Handbook of psychology (Vol. 12): Industrial and Organizational Psychology (333-375). New York: Wiley-Blackwell.

Kozlowski, S. W. J., \& Chao, G. T. (2012). Macrocognition, team learning, and team knowledge: Origins, emergence, and measurement. In E. Salas, S. M. Fiore, \& M. P. Letsky (Eds.), Theories of team cognition: Cross-disciplinary perspectives (pp. 19-48). New York, NY: Routledge. 
Kozlowski, S. W. J., \& Klein, K. J. (2000). A multi-level approach to theory and research in organizations: Contextual, temporal, and emergent processes. In K. J. Klein \& S. W. J. Kozlowski (Eds.), Multilevel theory, research, and methods in organizations. (pp.3-90). San Francisco: Jossey-Bass.

Künzle, B., Zala-Mezö, E., Kolbe, M., Wacker, J., \& Grote, G. (2010). Substitutes for leadership in anaesthesia teams and their impact on leadership effectiveness. European Journal of Work and Organizational Psychology, 19, 505-531. DOI:

$10.1080 / 13594320902986170$

LePine, J. A., Hollenbeck, J. R., Ilgen, D. R., Colquitt, J. A., \& Ellis, A. (2002). Gender Composition, Situational Strength, and Team Decision-Making Accuracy: A Criterion Decomposition Approach. Organizational Behavior and Human Decision Processes, 88, 445-475. DOI:10.1006/obhd.2001.2986

Liu, S., Hu, J., Li, Y., Wang, Z., \& Lin, X. (2014). Examining the cross-level relationship between shared leadership and learning in teams: Evidence from China. The Leadership Quarterly, 25, 282 - 295. DOI: 10.1016/j.leaqua.2013.08.006

Maruping, L. M., Venkatesh, V., Thatcher, S. M. B., \& Patel, P. C. (2015). Folding under pressure or rising to the occasion? Perceived time pressure and the moderating role of team temporal leadership. Academy of Management Journal, 58, 1313-1333. DOI: 10.5465/amj.2012.0468

Mathieu, J. E., Heffner, T.S., Goodwin, G. F., Salas, E., \& Cannon-Bowers, J. A. (2000). The influence of shared mental models on team process and performance. Journal of Applied Psychology, 85, 273-283. DOI: http://dx.doi.org/10.1037/0021-9010.85.2.273

Mathieu, J.E., \& Taylor, S.R. (2006). Clarifying conditions and decision points for mediational type inferences in Organizational Behavior. Journal of Organizational Behavior, 27, 1031-1056. DOI: 10.1002/job.406 
McClelland, G. H., Lynch, J. G., Irwin, J. R., Spiller, S. A., \& Fitzsimons, G. J. (2015).

Median splits, Type II errors, and false-positive consumer psychology: Don't fight the power. Journal of Consumer Psychology, 25, 679-689. DOI:

10.1016/j.jcps.2014.12.002.

Mohammed, S. \& Alipour, K. K. (2014). It's time for temporal leadership: Individual, dyadic, team, and organizational effects. Industrial and Organizational Psychology, 7, 178-203. DOI: 10.1111/iops.12128

Mohammed, S., Hamilton, K., Tesler, R., Mancuso, V., \& McNeese, M. (2015). Time for temporal team mental models: Expanding beyond "what" and "how" to incorporate "when”. European Journal of Work and Organizational Psychology. Advance online publication. DOI: http://dx.doi.org/10.1080/1359432X.2015.1024664

Mohammed, S., \& Nadkarni, S. (2011). Temporal diversity and team performance: The moderating role of team temporal leadership. Academy of Management Journal, 54, 489-508. DOI: 10.5465/AMJ.2011.61967991

Mohammed, S., \& Nadkarni, S. (2014). Are we all on the same temporal page? The moderating effects of temporal team cognition on the polychronicity diversity-team performance relationship. Journal of Applied Psychology, 99, 404-22. DOI: http://dx.doi.org/10.1037/a0035640

Mohammed, S., Ferzandi, L., \& Hamilton, K. (2010). Metaphor no more: A 15-year review of the team mental model construct. Journal of Management, 36, 876-910. DOI: $10.1177 / 0149206309356804$

Mohammed, S., Hamilton, K., \& Lim, A. (2009). The incorporation of time in team research: Past, current, and future. In E. Salas, G.F. Goodwin, \& C.S. Burke (Eds.), Team effectiveness in complex organizations: Cross-disciplinary perspective and approaches (pp. 321-348). New York: Routledge, Taylor \& Francis Group. 
Mohammed, S., Tesler, R., \& Hamilton, K. (2012). Time and shared cognition: Towards greater integration of temporal dynamics. In E. Salas, S.M. Fiore, \& M.P. Letsky (Eds.), Theories of team cognition: Cross disciplinary perspectives (pp. 87 - 116). New York: Routledge, Taylor and Francis Group.

Murase, T., Carter, D. R., DeChurch, L. A., \& Marks, M. A. (2014). Mind the gap: The role of leadership in multiteam system collective cognition. The Leadership Quarterly, 25, 972-986. DOI: http://dx.doi.org/10.1016/j.leaqua.2014.06.003

Muthén, L.K. \& Muthén, B.O. (2012). Mplus User’s Guide. Seventh Edition. Los Angeles, CA: Muthén \& Muthén.

Nübold, A., Muck, P. M., \& Maier, G. W. (2013). A new substitute for leadership? Followers' state core self-evaluations. The Leadership Quarterly, 24, 29-44. DOI: http://dx.doi.org/10.1016/j.leaqua.2012.07.002

Passos, A. M., \& Caetano, A. (2005). Exploring the effects of intragroup conflict and past performance feedback on team effectiveness. Journal of Managerial Psychology, 20, 231-244. DOI: 10.1108/02683940510589028

Podsakoff, P. M., MacKenzie, S. B., \& Bommer, W. H. (1996). Meta-analysis of the relationships between Kerr and Jermier's substitutes for leadership and employee job attitudes, role perceptions, and performance. Journal of Applied Psychology, 81, 380399. DOI: http://dx.doi.org/10.1037/0021-9010.81.4.380

Preacher, K. J., \& Hayes, A. F. (2008). Asymptotic and resampling strategies for assessing and comparing indirect effects in multiple mediator models. Behavior Research Methods, 40, 879-891. DOI: 10.3758/BRM.40.3.879

Rico, R., Sánchez-Manzanares, M., Antino, M., \& Lau, D. (2012). Bridging team faultlines by combining task role assignment and goal structure strategies. Journal of Applied Psychology, 97, 407-420. DOI:10.1037/a0025231 
Rico, R., Sánchez-Manzanares, M., Gil, F., \& Gibson, C. (2008). Team implicit coordination processes: A team knowledge-based approach. Academy of Management Review, 33, 163-84. DOI: 10.5465/AMR.2008.27751276

Rucker, D. D., McShane, B. B., \& Preacher, K. J. (2015). A researcher's guide to regression, discretization, and median splits of continuous variables. Journal of Consumer Psychology, 25, 666-678. DOI: 10.1016/j.jcps.2015.04.004

Santos, C. M, \& Passos, A.M. (2013). Team mental models, relationship conflict and effectiveness over time. Team Performance Management, 19, 363-385. DOI: http://dx.doi.org/10.1108/TPM-01-2013-0003

Santos, C.M., Uitdewilligen, S., \& Passos, A.M. (2015a). Why your team is more creative than mine? - The influence of shared mental models on intragroup conflict, team creativity and effectiveness. Creativity and Innovation Management, 24, 645-658. DOI: $10.1111 /$ caim.12129

Santos, C.M., Uitdewilligen, S., \& Passos, A.M. (2015b). A temporal common ground for learning: The moderating effect of shared mental models on the relation between team learning behaviours and performance improvement. European Journal of Work and Organizational Psychology, 24, 710-725. DOI: 10.1080/1359432X.2015.1049158

Schmidt, R.C., Bienvenu, M., Fitzpatrick, P.A., \& Amazeen, P.G. (1998). A comparison of intra- and interpersonal interlimb coordination: Coordination breakdowns and coupling strength. Journal of Experimental Psychology: Human Perception and Performance, 24, 884-900. DOI: http://dx.doi.org/10.1037/0096-1523.24.3.884

Schreiber, J. B., Stage, F. K., King, J., Nora, A., \& Barlow, E. A. (2006). Reporting structural equation modeling and confirmatory factor analysis results: A review. The Journal of Educational Research, 99, 323-337. DOI: 10.3200/JOER.99.6.323-338 
Shah, P.R. \& Jehn, K.A. (1993). Do friends perform better than acquaintances? The interaction of friendship, conflict, and task. Group Decision and Negotiation, 2, 149166. DOI: http://dx.doi.org/10.1007/BF01884769

Shamir, B. (2011). Leadership takes time: Some implications of (not) taking time seriously in leadership research. The Leadership Quarterly, 22, 307-315. DOI: 10.1016/j.leaqua.2011.02.006

Siemsen, E., Roth, A. \& Oliveira, P. (2010). Common method bias in regression models with linear, quadratic, and interaction effects. Organizational Research Methods, 13, 456476. DOI: $10.1177 / 1094428109351241$

Spector, P.E. (2006). Method variance in organizational research: Truth or urban legend?. Organizational Research Methods, 9, 221-232. DOI: 10.1177/1094428105284955

Standifer, R. L., Raes, A.M.L., Peus, C., Passos, A.M., Santos, C.M., \& Weisweiler, S. (2015). Time in teams: cognitions, conflict and team satisfaction. Journal of Managerial Psychology, 30, 692-708 DOI: 10.1108/JMP-09-2012-0278

Tabernero, C., Chambel, M. J., Curral, L. \& Arana, J. M. (2009). The role of task-oriented versus relationship-oriented leadership on normative contract and group performance. Social Behavior and Personality, 37, 1391-1404. DOI: 10.2224/sbp.2009.37.10.1391

Uitdewilligen, S., Waller, M.J, \& Pitariu, A.H. (2013). Mental model updating and team adaptation. Small Group Research, 44, 127-158. DOI: 10.1177/1046496413478205

Van der Erve, M. (2004). Temporal leadership. European Business Review, 16, 605-617. DOI: http://dx.doi.org/10.1108/09555340410565422

Waller, M. J., Conte, J. M., Gibson, C. B., \& Carpenter, M. A. (2001). The effect of individual perceptions of deadlines on team performance. Academy of Management Review, 26, 586-600. DOI: 10.5465/AMR.2001.5393894 
Wheelan, S. A. (2009). Group size, group development, and group productivity. Small Group Research, 40, 247-262. DOI: 10.1177/1046496408328703

Wooldridge, J. M. (2013). Introductory econometrics: A modern approach (5th ed.). Mason, OH: South-Western, Centage Learning.

Yang, Z. (2009). Temporal conflict in teams: Antecedents, regulatory mechanisms, and outcomes. PhD thesis, Pennsylvania State University, University Park.

Yukl, G. A. (2010). Leadership in Organizations ( $7^{\text {th }}$ ed.). Upper Saddle River, NJ: Pearson.

Zaccaro, S. J., Rittman, A. L., \& Marks, M. A. (2001). Team Leadership. The Leadership Quartely, 12, 451- 483. DOI: 10.1016/S1048-9843(01)00093-5

Zhou, J. (2003). When the presence of creative coworkers is related to creativity: Role of supervisor close monitoring, developmental feedback, and creative personality. The Journal of Applied Psychology, 88, 413-422. DOI: http://dx.doi.org/10.1037/00219010.88.3.413. 
Table 1.

Means, standard deviations, and correlations among all team-level variables

\begin{tabular}{|c|c|c|c|c|c|c|c|c|c|c|c|c|}
\hline & M & SD & 1 & 2 & 3 & 4 & 5 & 6 & 7 & 8 & 9 & 10 \\
\hline 1. Task experience & 0.51 & 0.93 & & & & & & & & & & \\
\hline 2. Team size & 4.58 & 0.67 & .07 & & & & & & & & & \\
\hline 3. Students & 0.41 & 0.49 & -.10 & $-.17^{*}$ & & & & & & & & \\
\hline 4. Workers & 0.45 & 0.50 & .16 & .01 & $-.75^{* * *}$ & & & & & & & \\
\hline 5. Mixed & 0.14 & 0.35 & -.08 & $.22^{* *}$ & $-.34^{* * *}$ & $-.37^{* * *}$ & & & & & & \\
\hline 6. Age & 29.14 & 7.30 & $.23^{* *}$ & .10 & $-.54^{* *}$ & $.62^{* *}$ & -.12 & & & & & \\
\hline 7. Male percentage & 68.40 & 25.73 & .01 & -.14 & -.00 & .00 & .01 & .07 & & & & \\
\hline 8. Temporal leadership & 5.42 & 0.93 & -.04 & .03 & -.03 & .07 & -.06 & .00 & -.14 & & & \\
\hline 9. STC & 5.58 & 0.64 & .10 & .04 & $-.29^{* * *}$ & $.20^{*}$ & .12 & $.27^{* *}$ & -.12 & $.43^{* * *}$ & & \\
\hline 10. Temporal conflict & 2.09 & 0.78 & -.05 & .11 & $.21^{*}$ & -.12 & -.12 & -.16 & .09 & $-.50^{* * *}$ & $-.45^{* * *}$ & \\
\hline 11. Team performance & 2.07 & 0.21 & .07 & .03 & $-.29^{* *}$ & $.26^{* *}$ & .03 & $.26^{* *}$ & .01 & $.20^{*}$ & $.23^{* *}$ & $-.29^{* *}$ \\
\hline
\end{tabular}

Note. $\mathrm{n}=142$ teams. $\mathrm{STC}=$ Shared temporal cognitions. $* p<.05 ; * * p<.01 ; * * * p<.001$ 
Table 2.

Results for the interaction effect of temporal leadership and shared temporal cognitions on temporal conflict

\section{Temporal conflict}

\begin{tabular}{lccc}
\hline Variables & $B$ & SE $B$ & $R^{2}$ \\
\hline Intercept & $2.09 * * *$ & .09 \\
Task experience & -0.07 & .06 \\
Team size & $0.22^{*}$ & .09 \\
Students & 0.10 & .15 \\
Mixed & $-0.40 *$ & .17 \\
Age & -0.01 & 0.01 \\
Male percentage & 0.00 & 0.00 \\
Temporal leadership & $-0.32 * * *$ & .07 \\
STC & $-0.23 *$ & .10 \\
Temporal leadership x STC & $0.22^{*}$ & .09 \\
& & .42 \\
\hline
\end{tabular}

Note. $\mathrm{n}=142$ teams. STC = Shared temporal cognitions. 'Students' and 'Mixed' refer to two dummy variables that were built for the categorical variable 'team composition'. 'Task experience' and 'Age' refer to team means of the respective variables. * $p<.05$; *** $p<.001$ 


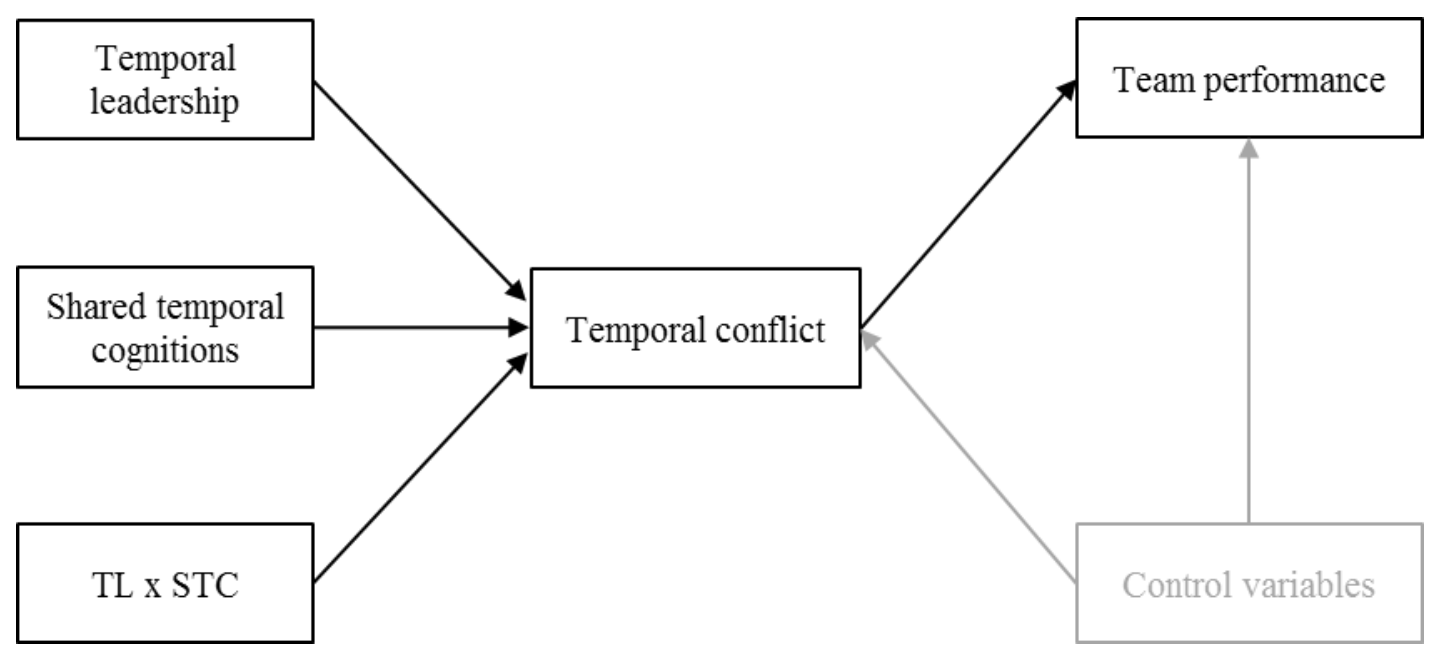

Figure 1. Research model. The model was tested in two separate analyses. First, we analyzed the mediating mechanism of temporal conflict in the relationship of temporal leadership (Hypothesis 1) and shared temporal cognitions (Hypothesis 2) on team performance. Second, we analyzed the moderating influence of shared temporal cognitions on the relationship between temporal leadership and team performance (Hypothesis 3), and the interaction effect of temporal leadership and shared temporal cognitions on performance via temporal conflict (Hypothesis 4).

Control variables include team size, task experience, team composition (dummy variables 'students' and 'mixed'), gender, and age composition. STC = shared temporal cognitions; TL $=$ temporal leadership. 


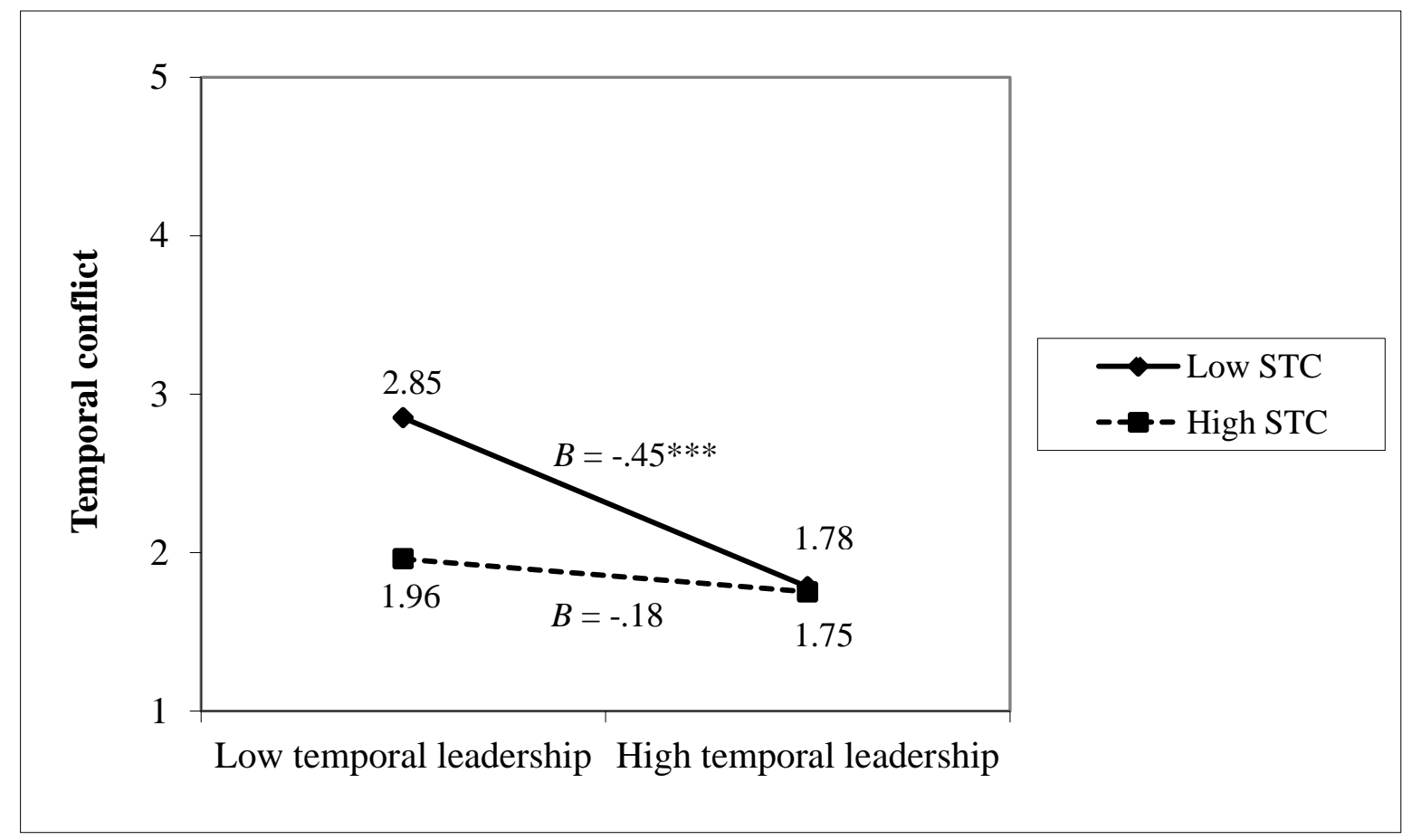

Figure 2. The interaction effect between shared temporal cognitions (STC) and temporal leadership on temporal conflict.

Note. $* * * p<.001$ 